\title{
Ímpetu y sueño del arte norteamericano en los escritos de Aguilera Cerni ${ }^{1}$
}

\author{
Carmen BERNÁRDEZ SANCHís \\ Universidad Complutense de Madrid \\ carbernardez@ghis.ucm.es
}

Recepción: 16 de febrero de 2010 / Revisión: 16 de junio de 2010

Aceptación: 20 de junio de 2010 / Publicación: diciembre de 2010

\begin{abstract}
RESUMEN
El tema del presente texto se centra en los dos libros que escribió el crítico e historiador Vicente Aguilera Cerni en 1955 y 1957 sobre el arte de los Estados Unidos de América. A través de ellos y de las circunstancias históricas que los rodearon, analizaremos su interpretación y la manera en que este "descubrimiento" del arte norteamericano se insertó en el ambiente artístico de la dictadura franquista. Los libros de Aguilera Cerni fueron escritos en un periodo de la historia española comprendido entre el acuerdo y el abrazo; el "acuerdo" económico y militar suscrito por los gobiernos de España y Estados Unidos en 1953, y el "abrazo" que se produjo entre Franco y el presidente Eisenhower en 1959. Si bien el legado teórico de Aguilera Cerni es reconocido en la actualidad, ha sido todavía insuficientemente estudiado. Este trabajo se propone analizar uno de los aspectos menos conocidos de su aportación a la historia del arte, que posee un carácter innovador al presentar al público español, con una perspectiva abierta y progresista, unas creaciones artísticas casi desconocidas entonces y de las que no había estudios realizados en nuestro país, siendo también escasas las traducciones de textos de autores internacionales.
\end{abstract}

Palabras clave: Historia del Arte, Aguilera Cerni, Estados Unidos de América, identidad, pintura, siglo XX.

\section{Impetus and the Dream of American Art in the Works of Aguilera Cerni}

\begin{abstract}
The present text focuses on two books about art from the United States written by critic and historian Vicente Aguilera Cerni in 1955 and 1957, respectively. Through them, and the historical circumstances surrounding them, we analyze how U.S .art was interpreted during the Franco regime, and the role it played in Spanish art circles after its "discovery." Aguilera Cerni's books were written in a period of Spanish history running between accord and embrace, a phrase associated with political relations between Spain and the United States in the 1950s. In that context, "accord" refers to economic and political accords signed by the governments of Spain and the United States in 1953. The subsequent "embrace" took place between Franco and President Eisenhower in 1959. While Aguilera Cerni's theoretical legacy is now recognized, it has yet to be sufficiently studied. The present text analyzes one of his leastknown and most innovative contributions to art history: his open and progressive presentation to the Spanish public of U.S. artistic creations practically unknown in Spain at that time. Those works had never been studied here and very few of the studies by foreign authors had yet been translated.
\end{abstract}

Keywords: Art History, Aguilera Cerni, United States of America, Identity, Painting, 20th Century.

${ }^{1}$ El presente texto se inscribe dentro del Proyecto de Investigación del Ministerio de Ciencia y Tecnología, Dirección General de Investigación y Gestión del Plan Nacional de I + D y la Universidad Complutense de Madrid HAR2009-13284, Construcción y comunicación de identidades en la historia de las relaciones internacionales: dimensiones culturales de las relaciones entre España y los Estados Unidos. 
SUMARIO: 1. Algunos datos sobre Vicente Aguilera Cerni. 2. Entre el acuerdo y el abrazo. 3. Escribir sobre arte de Estados Unidos. 4. La identidad del arte norteamericano: una cuestión a dilucidar. 5. Recorridos visuales y estéticos. 6. El arte de Estados Unidos, entre el realismo y la abstracción. 7. Conclusiones. 8. Referencias bibliográficas.

\section{ALGUNOS DATOS SOBRE VICENTE AGUILERA CERNI}

Nacido en Valencia en 1920, Vicente Aguilera Cerni fue uno de los críticos de arte que mayor proyección internacional tuvo desde los años cincuenta hasta su muerte en 2005. Tras estudiar Derecho y Filosofía y Letras en la Universidad de Valencia, se dedicó a la crítica de arte, favoreciendo y apoyando decididamente iniciativas de vanguardia como las propuestas por los grupos Parpalló y Equipo Crónica. Sus escritos le valieron diversos reconocimientos nacionales e internacionales, como la concesión, en 1959, del Primer Premio Internacional de la Crítica en la XXIX Bienal de Venecia, y el Premio Pi Suñer a la mejor labor cultural sobre temas norteamericanos ${ }^{2}$. En 1995 le fue otorgada la medalla de Oro de la Presidencia del Consejo de Ministros de Italia, y en 2000 el Premio de las Letras Valencianas. En sus últimos años, Aguilera Cerni fue presidente de honor de la Asociación Española de Críticos de Arte, Académico de Bellas Artes de San Carlos y Doctor Honoris Causa por la Universidad Politécnica de Valencia. Fue fundador y director del Museo de Arte Contemporáneo "Vicente Aguilera Cerni" de Vilafamés (Castellón), y también fundador de la revista Suma y sigue del arte contemporáneo. Editada entre 1963 y 1967, fue una revista especializada de gran proyección y relevancia en el mundo artístico español. Sus muchas publicaciones incluyen monografías de artistas, artículos de crítica de arte, prólogos, ensayos y diversos libros, como La aventura creadora (1955), Panorama del nuevo arte español (1966), El arte impugnado (1969), Iniciación al arte español de la posguerra (1970), Arte y popularidad (1973), Arte y compromiso histórico (1976), Posibilidad e imposibilidad del arte (1973), o Textos, pretextos y notas: Escritos escogidos, 1953-1987 (1987).

\section{ENTRE EL ACUERDO Y EL ABRAZO}

Las relaciones entre España y Estados Unidos habían sido prácticamente inexistentes en la década de los cuarenta. Los países aliados durante la Segunda Guerra Mundial rechazaban un gobierno ilegítimo y fascista surgido de un golpe de estado y afín a los países del Eje, aunque durante la contienda se había mantenido aparentemente neutral. España había cerrado sus puertas, pensando que podría sobrevivir e incluso crecer en condiciones de casi total aislamiento, en pos de un destino -decía la falaz propaganda franquista- "universal" que todos acabarían por reconocer. El presidente norteamericano Harry S. Truman no quiso formalizar ninguna relación con Franco, mostrando siempre desconfianza e incluso aversión hacia él y lo que sig-

2 El Premio "Doctor José María Pi y Suñer" lo otorgaba el Instituto de Estudios Norteamericanos de Barcelona a ensayos sobre la vida cultural de Estados Unidos publicados en la prensa española. El Instituto, dependiente de la embajada de EEUU, fue inaugurado en mayo de 1952, con José Ma Pi y Suñer como presidente. En su primera edición, en 1954, le fue concedido el premio a Julián Marías. 
nificaba el régimen. El estancamiento económico, la escasez de productos alimenticios, la represión política y el atraso en todos los ámbitos, además de la nefasta política exterior, habían llevado al país a un estado de postración y miseria.

En la década de los cincuenta la situación va a cambiar, no por voluntad política de apertura por parte del régimen franquista, sino por razones estratégicas derivadas de la Guerra Fría entre Estados Unidos y la Unión Soviética. Las previsiones de los Estados Unidos respecto a España dieron un giro importante y, aunque el famoso Plan Marshall no llegó como tal, sí se implementaron algunos préstamos y ayudas económicas que fueron el preludio de los acuerdos de 1953. España no tendría que democratizarse para ser tenida en consideración internacionalmente. Ahora había un aspecto que conectaba los intereses españoles con los norteamericanos: el anticomunismo. Sin embargo, era preciso introducir algunos cambios liberalizadores en la política franquista. Las nuevas expectativas de tibia apertura se vieron favorecidas por el triunfo electoral de Eisenhower en noviembre de 1952.

Los acuerdos económicos y militares España-Estados Unidos, conocidos como "Pacto de Madrid", se firmaron el 26 de septiembre de 1953 en el Palacio de Santa Cruz de Madrid. La delegación norteamericana fue presidida por el embajador en Madrid, James C. Dunn. La española, por el ministro de Asuntos Exteriores, Alberto Martín Artajo. Estuvieron presentes también el jefe de la misión militar en España, general Kissner, y el director de la Cámara de Comercio de EE.UU. en España. Con estos acuerdos Franco vería reconocido internacionalmente su régimen y liquidado el largo boicot diplomático al que había sido sometido el país en años anteriores ${ }^{3}$.

Un anuncio publicitario de los almacenes Sepu mostraba en 1939 una mano derecha alzada, haciendo el saludo fascista. En torno a la muñeca se enredaba el nombre de los almacenes y en la parte inferior se leía: "Sepu... saluda con entusiasmo a la ESPAÑA [sic] que renace"4. Este "renacer" se vio propiciado por el final de la autarquía y la actitud favorable de los Estados Unidos, que tras diversas reticencias (sobre todo debidas a la cerrazón de Franco y su equipo) pudieron culminar las negociaciones por las cuales ellos instalarían sus bases militares en España, y los españoles recibirían ayuda económica. La publicidad de los años cincuenta da testimonio de la introducción creciente de productos norteamericanos como el chicle, los cigarrillos rubios Winston, la Coca Cola -que empezaría a producirse en 1953 en una fábrica de Barcelona- $\mathrm{y}$ otros bienes que la nueva amistad con los Estados Unidos estaba introduciendo poco a poco en los hogares españoles 5 .

El régimen pudo establecer desde el arranque de la década de los cincuenta diversas vías de comunicación con el exterior: las relaciones político-militares con Estados Unidos, las eclesiásticas a través del Concordato firmado con el Vaticano, también en 1953, además de su incorporación a la OMS, la UNESCO y en 1955 -el mismo año de Introducción a la pintura norteamericana, de Aguilera Cerni- a la $\mathrm{ONU}^{6}$. Además, desde principios de la década España se había convertido en un des-

\footnotetext{
3 JARQUe, 1998, pp. 337-363; PAYNe, 2003, pp. 161-163; Viñas, 1981 y 2003.

4 SueIro, 2008, p. 27.

5 Ibidem, p. 236.

6 Lleonart AmséLEM, 1995.
} 
tino turístico deseable. Diversas campañas propagandísticas tuvieron como objetivo restablecer, a través del turismo, la comunicación con el exterior, con el objetivo final de que el régimen franquista fuese reconocido. La Dirección General de Turismo invitó a diversas personalidades internacionales a visitar España. Entre ellas, en 1950, a una delegación de periodistas norteamericanos. Tiene interés reseñar que en su visita a Madrid fueron conducidos al Escorial y al Museo de Perico Chicote en lugar de al Museo del Prado - que sería lógico dada la magnitud cultural de la pinacoteca-, siendo también invitados a presenciar un espectáculo taurino 7 . Se quería mostrar al mundo una España "moderna", pero sin prescindir de la parafernalia típica y folklórica como imagen rentable de un país habitado todavía por toreros y gitanas; tipismo nacional que se ofrecía como aliciente pintoresco a los turistas extranjeros. Este tipismo para la exportación coincidía en nuestro suelo con su homólogo americano, presente en muchos productos y anuncios publicitarios, en los kioscos de prensa con las novelitas populares de vaqueros escritas por el español Marcial Lafuente Estefanía (1903-1984) y, por supuesto, en las pantallas cinematográficas con las películas de Walt Disney ${ }^{8}$ y los westerns ${ }^{9}$. De todo esto hallamos noticia en revistas generalistas de los años cincuenta como Nuestro Tiempo. La incorporación del tópico americano en las vidas de los españoles de los años cincuenta, contó también con algunas iniciativas por parte de directores de cine españoles que buscaron para sus películas ambientaciones en los Estados Unidos. Tal fue el caso de Senda ignorada, de 1946, primera película de José Antonio Nieves Conde (1915-2006). Se trataba de una historia de gángsters que tenía lugar supuestamente en Estados Unidos, protagonizada por Alicia Palacios y Enrique Guitart. En 1957 Ladislao Vajda dirigió Un ángel pasó por Brooklyn, protagonizada por Pablito Calvo y Peter Ustinov, que fue rodada en un escenario de Madrid que reproducía ese barrio neoyorkino. Su argumento, entre la magia sobrenatural y la descripción de tipos, le valió a la película ser declarada de "Interés Nacional". No hemos de olvidar tampoco la presencia de los estadounidenses en la trama de Bienvenido Mr. Marshall, de Luís García Berlanga (1921) realizada en 1952 y que obtuvo mención especial del Festival de Cannes al año siguiente. En esta obra la mirada se vuelve mordaz, desafiando la omnipresente censura. Berlanga ironiza sobre la supuesta llegada inminente del país benefactor, Estados Unidos, a un pequeño pueblo. La película hace referencia al Plan Marshall (European Recovery Program) que estaba siendo implantado en otros países europeos desde 1947, pero no en España.

Aguilera Cerni escribió su segundo libro en 1957, dos años antes del Plan de Estabilización. Obligado a tomar medidas liberalizadoras, el régimen inició una apertura que se vio impulsada desde dentro con la gran remodelación del gobierno que tuvo lugar en 1957, y que situó en puestos de poder a una generación de políticos tecnócratas decididos a incorporar al país al modelo económico occidental. Ese año sería fundamental también desde el punto de vista de la actividad artística, ya que parte del nuevo programa político sería la potenciación y proyección internacio-

\footnotetext{
7 Correyero, 2003, pp. 47-61.

8 Collar, 1955, pp. 100-113 y 1957, pp. 453-454; E. R, 1961, p. 523.

${ }^{9}$ Farré Gual, 1955, pp. 41-49; Farré Gual, 1959, pp. 98-104.
} 
nal del arte moderno que se hacía en España. La relación entre España y Estados Unidos se selló con la escenificación pública del abrazo entre los dos mandatarios. Este encuentro se produjo, con todos los honores y asistencia masiva de público, cuando Eisenhower llegó a Madrid el 21 de diciembre de 1959. Era una escala más de un largo viaje, pero resultaba muy significativo que un presidente de los Estados Unidos visitara España por primera vez, gesto político que mostraba la voluntad de afianzar las relaciones mutuas.

\section{ESCRIBIR SOBRE ARTE DE ESTADOS UNIDOS}

Cuando en 1955 Vicente Aguilera Cerni publicó el primero de sus libros, Introducción a la pintura norteamericana, la nota de la editorial valenciana que lo publicó, Fomento de Cultura, lo presentó como "el primer libro que escribe un autor español sobre este tema y el primero - de los publicados en España- que llega hasta nuestros días"10. El libro está ilustrado con cuarenta y dos reproducciones en blanco y negro seleccionadas con un criterio bien fundamentado, sobre el que volveremos más adelante. La bibliografía cita primeras ediciones en inglés a excepción de dos títulos, uno de John Walker (1906-1995) que había sido traducido al castellano en $1954^{11}$, y otro del escritor argentino Julio E. Payró (1899-1971) ${ }^{12}$. Remite Aguilera a autores norteamericanos que eran entonces renombrados historiadores del arte, profesores y directores de museos que publicaron obras sobre arte de Estados Unidos: Oliver W. Larkin (1896-1970) ${ }^{13}$, Frederick S. Wight (1902-1986) ${ }^{14}$, James Thomas Flexner (1908-2003) $)^{15}$, Virgil Barker (1890-1965) ${ }^{16}$, Andrew Carnduff Ritchie (1907-1978) ${ }^{17}$ y Thomas B. Hess (1920-1978) ${ }^{18}$. Cita también tres artículos propios de 1954, en los que comenta la participación de los artistas americanos en la Bienal de Venecia de ese año. Esta bibliografía puede darnos idea de la cuidadosa preparación de los dos libros, ya que partió de fuentes americanas escritas en los últimos años de la década del cuarenta y primeros de la del cincuenta, lo cual podemos considerar un mérito añadido, dada la dificultad reinante en España para hacerse con información bibliográfica actualizada. Aunque Aguilera sería becario del gobierno francés en París en $1957^{19}$-donde podría tener un acceso más directo y libre a publicaciones internacionales- esta bibliografía fue consultada y publicada años antes, lo cual no hace sino resaltar la labor investigadora de Aguilera en cuestiones muy actua-

10 Aguilera CERNi, 1955 (cubierta).

11 WALKeR, 1954.

12 PAYRÓ, 1946.

13 LARKIN, 1949.

14 Wight, 1949.

15 FLEXNER, 1947.

16 BARKER 1950.

17 CARnduff Ritchie, 1951 (aunque figura equivocadamente la fecha de 1921 en el libro de Aguilera).

18 HeSs, 1951.

19 Datos biográficos actualizados pueden consultarse en www.upv.es/organizacion/conoceupv/honoris-causa/vicente-aguilera/biografia-en.html (acceso diciembre 2009). 
les. La reflexión sobre la naturaleza de un arte específico de los Estados Unidos y su disciplina histórica estaba, cuando escribe Aguilera, todavía "en construcción". Si bien en los cincuenta el arte americano posterior a la Segunda Guerra Mundial (la escuela de Nueva York y el Expresionismo Abstracto) estaba siendo reconocido mundialmente como un arte original y de gran influencia en el panorama internacional, la producción artística anterior era poco conocida y valorada. Por ello abordar, como hizo Aguilera Cerni, todo el desarrollo cronológico desde casi la época colonial, respondía claramente al deseo de transmitir al lector la base histórica, el tejido socio-cultural y creativo que respaldaba la solidez del arte posterior. Se trataba, en suma, de hacer ver que el gran arte americano de la escuela de Nueva York, ni era una copia del europeo ni había surgido en suelo americano por generación espontánea. Por el contrario, partía de una red de tendencias y planteamientos estéticos -la propia tradición artística estadounidense- de más largo recorrido, aunque nadie negara la influencia de los artistas europeos. Los libros de Aguilera, así como los de otros estudiosos no norteamericanos, contribuyeron a la difusión y la internacionalización del arte de Estados Unidos.

De esta manera, entre las razones que movieron al crítico valenciano a escribir sus libros estaba el deseo de dar a conocer las creaciones artísticas del país al que España se estaba aproximando, del cual incorporaba aspectos concretos de su contemporaneidad pero sin saber casi nada de su historia. Tal como señalaba Aguilera en su Introducción a la pintura norteamericana, una razón importante era el deseo de rebatir el arraigado prejuicio de que se trataba de una gran potencia sin historia, y cuyo arte carecía de originalidad:

Esa fácil apreciación es la de que la pintura norteamericana -en bloque y sin excepción alguna- es algo así como una tosca imitación reiterativa de la europea ${ }^{20}$.

Aguilera destacó la frecuencia con la que aparecía este prejuicio, comparándolo con la actitud, mezcla de soberbia y envidia, del aristócrata arruinado frente al "nuevo rico". Al hacer esta comparación no se limitaba a España, pues también la hacía extensible a la "vieja" Europa. Tal prejuicio era consecuencia de las reticencias de muchos a aceptar totalmente a un país joven que se imponía con fuerza en el concierto internacional. Estados Unidos era el país benefactor, la "primera potencia mundial" que lideraba el bloque occidental. Modelo económico de desarrollo, era todavía bastante desconocido, pese a que algunas revistas fundadas en España durante la primera mitad de la década dedicaron atención especial a dar a conocer su sistema electoral, su economía, su política exterior, su cinematografía, su literatura, su psicología y también su arte. Todo aquello que permitiera conocer mejor al país que iba a establecer sus bases en suelo español. Todo, menos lo que pudiera interpretarse como promoción de su sistema democrático.

Estados unidos se pudo de moda. En 1954 se había traducido Las 48 Américas, libro del periodista francés Raymond Cartier (1904-1975), corresponsal en Nueva York de Samedi Soir y fundador de Paris Match. En el primer número de la revista Nuestro Tiempo se publicaba una reseña de este libro:

20 Aguilera Cerni, 1955, p. 7. 
Norteamérica está de moda. Y este libro de Raymond Cartier es, sin duda, la mejor introducción de que dispone un lector europeo para comprender el nuevo y complejo fenómeno político y humano que los Estados Unidos representan en el mundo [...] En pocos años se ha desarrollado en un territorio que para nuestra escala europea equivale a un continente, con los más diversos climas, los más variados orígenes históricos y la más heterogénea población; una nación que muestra al mundo, sin embargo, un excepcional ejemplo de unidad política y de espíritu ${ }^{21}$.

No era en realidad un país tan "nuevo" ni había surgido, como daba a entender el articulista, "en pocos años". Pero la idea tópica de que se trataba de una nación sin historia, joven o incluso adolescente, estaba muy extendida. Al público español se le transmitía la imagen de una nación reciente, haciendo caso omiso de la historia que había marcado el desarrollo de la democracia americana. Este aspecto, así como la presencia estadounidense en las guerras mundiales, la posguerra, la de Corea y la Guerra Fría, y desde luego la colaboración de los brigadistas con la República española durante la Guerra Civil, eran desdibujados ante la imagen de nación joven sin tradiciones que en los años cincuenta tanto se publicitó. Muchos aceptaron de buen grado su liderazgo político y económico, reconociéndoles su energía emprendedora, su riqueza e influencia internacional. Otra cosa era aceptar sin más su influencia cultural. En España, el arte norteamericano fue sometido a juicios categóricos, siendo considerado menor de edad hasta el punto de que Aguilera Cerni creyó necesario insistir en reiteradas ocasiones sobre la madurez artística del pueblo más poderoso del mundo. De ahí que calificara de "ridícula y suicida" la actitud despectiva e ignorante de muchos, y que dedicara atención a describir un contexto histórico más comprensivo:

Los Estados Unidos han vivido pruebas muy duras. Su historia no ha sido un plácido desfile o un tranquilo paseo, pues pese a su brevedad, el pueblo norteamericano conoce la adversidad y el sufrimiento. Dentro de nuestro siglo ha participado en dos guerras mundiales y padecido una terrible depresión económica [...] Prosperidad, democracia, seguridad, supervivencia, cuanto integraba la razón de ser de todo un pueblo, estuvo en peligro. El periodo comprendido entre las dos grandes guerras tiene la sima pavorosa de la depresión. Así pues, la muerte y la miseria no son vagas referencias para los norteamericanos actuales, sino algo real, vivo y posible 22 .

Tal como relató años más tarde, los juicios de valor arbitrarios, construidos sobre el desconocimiento, eran excesivamente frecuentes:

Naturalmente, el problema de los años 50 no consistía - ni consiste ahora- en trasladar métodos de interpretación al campo de la producción artística, sino en el establecimiento de un substrato cultural sobre el que apoyarse para salir de la arbitrariedad de los juicios y de la fase que obligaba a explicar constantemente nociones absolutamente elementales sobre el repertorio de las tendencias modernas 23 .

\footnotetext{
21 A. F., 1954, pp. 125-126.

22 Aguilera Cerni, 1957, pp. 20-21.

23 Aguilera Cerni, 1976, p. 38.
} 
Aguilera Cerni animaba a sus lectores a considerarlo como algo cercano, incluso propio, dadas las afinidades que encontraba pero que en ningún momento llegó a explicar:

[...] sería mucho más sensato estimular el conocimiento y desarrollo de algo que podemos considerar nuestro $-\mathrm{o}$ al menos afín- por muchos conceptos ${ }^{24}$.

No duda en conferir al arte de Estados Unidos el prestigio de haber desarrollado una escuela propia de pintura, cuando algunas fuertes personalidades artísticas -John Singleton Copley (1738-1815), Benjamin West (1738-1820) y John Trumbull (17561843) - fueron capaces, desde principios del siglo XIX, de salvar a la producción artística del "bache donde se había estancado"25. Puede parecer sorprendente que Aguilera dedique un solo párrafo a la relación escueta de pintores de la Hudson River School, una aportación verdaderamente característica pues, aunque sus raíces se hundían en la tradición paisajística del Romanticismo europeo, los paisajes eran puramente americanos y el espíritu a ellos asociado poseía el significado religioso y nacionalista que le confirieron los primeros colonos: el de ser el paraíso terrenal, la tierra prometida. Sin embargo, el conocimiento y la recuperación de esta escuela de paisaje americana ha sido en Europa un fenómeno tardío ${ }^{26}$. Respecto a la arquitectura, Aguilera Cerni sitúa el origen de la escuela norteamericana -que sólo analiza en el segundo de sus libros- con las primeras soluciones constructivas en madera -ballom-frame- desarrolladas como adaptación a los distintos medios geográficos $\mathrm{y}$, de forma más "oficial", con el desarrollo del rascacielos en la Escuela de Chicago y con la arquitectura orgánica de Frank Lloyd Wright (1867-1959), pionero del movimiento moderno ${ }^{27}$.

\section{LA IDENTIDAD DEL ARTE NORTEAMERICANO: UNA CUESTIÓN A DILUCIDAR}

El argumento de que el arte de los Estados Unidos era una imitación del europeo no era nuevo ni infundado, pues buena parte de la historiografía artística apreciaba sólo la creación de los más grandes pintores de los siglos XVIII a XIX que procedían de Europa o se formaron o afincaron en ella, considerando las creaciones anteriores como episodios de calidad mucho menor. La realidad es que muchos de sus artistas habían nacido en Europa, y el flujo de llegada no se detuvo desde los primeros Padres Peregrinos hasta los años setenta del siglo XX. Aguilera Cerni no se ocupó mucho del arte colonial; tan sólo una breve referencia en el primero de sus libros, Introducción a la pintura norteamericana, para ofrecer una visión panorámica. Tomó como punto de partida real de su discurso lo que consideraba una escuela constituida ya con cierta madurez artística. Bajo esa perspectiva, era claro que esa madurez se sustentaba en el buen aprendizaje de los modelos por antonomasia: el arte clásico y sobre todo la pintura inglesa y francesa. Los artistas estadounidenses del siglo

\footnotetext{
24 Aguilera Cerni, 1955, pp. 8-9.

25 Ibídem, p. 14.

26 García Felguera, 2001, pp. 47-61.

27 Aguilera Cerni, 1957, pp. 32-33.
} 
XIX dieron la espalda a lo autóctono o nativo, para viajar a las academias europeas de Bellas Artes y obtener una formación artística completa. Algunos de los que viajaron a Europa para estudiar pintura o realizar su Grand Tour por los museos del viejo continente, se instalaron en Europa como emigrados de lujo. Tal fue el caso de James Whistler (1834-1903), John Singer Sargent (1856-1925) y Mary Cassatt (1844-1926). En el polo opuesto al cosmopolitismo de estos tres artistas, la creación pictórica de los llamados American Primitives respondía a su muy limitada formación artística en una nación incipiente, sin academias y sin otros modelos reconocidos que los que llegaban a las colonias en forma de grabados de reproducción, generalmente de la pintura retratística inglesa. Los retratos de la pintura estadounidense de primera hora, marcados por una ejecución torpe en términos generales -que Aguilera Cerni califica diplomáticamente como "cierta rudeza psicológica"28 - se completan en su relato con el primitivismo ingenuista de Edward Hicks (1780-1849), en cuya obra ve el crítico "un buscar honrada y sencillamente la voz propia"29.

Desde el final de la Guerra de Independencia en adelante muchos se habían interrogado acerca de la identidad "americana": ¿cuáles son los rasgos, las cualidades puramente americanas? La necesidad de construir una identidad nacional que se manifestara nítidamente, distinguiéndose de las demás, no parecía realmente posible. Al menos así lo expresó Mark Twain en 1895:

There isn't a single human characteristic that can be safely labeled "American". There isn't a single human ambition, or religious trend, or drift of thought, or peculiarity of education, or code of principles, or breed of folly, or style of conversation, or preference for a particular subject for discussion, or form of legs or trunk or head or face or expression or complexion, or gait, or dress, or manners, or disposition, or any other human detail, inside or outside, that can rationally be generalized as "American"30.

Aguilera reconoce la dificultad que entraña tal definición, pero al enumerar las causas de esta dificultad está, en realidad, definiendo lo que vislumbra como rasgos esenciales, que reaparecerán a lo largo de sus escritos. Sea lo que sea el arte estadounidense, se alimenta del dinamismo y variedad de su sociedad y del determinismo de su geografía:

El mayor problema del arte norteamericano radica en la búsqueda del idioma para expresar el ímpetu, la violencia y el sueño de unas tierras que vivían en plena prehistoria cuando llegaron los primeros colonizadores europeos ${ }^{31}$.

La esencia compleja del pueblo estadounidense será definida por él en otro texto, mediante una metáfora geológica, como "pueblo formado torrencialmente, recibiendo múltiples aluviones" 32 . Esta característica vitalidad y capacidad emprendedora

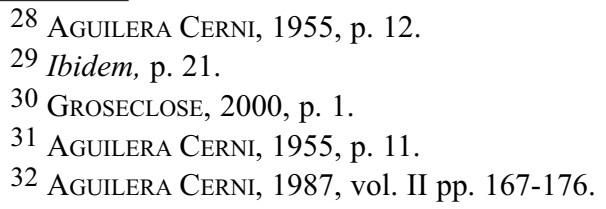


del pueblo americano es reiterada no sólo por el crítico valenciano, sino por otros muchos autores. Se vincula directamente al "factor juventud" que mencionábamos más arriba, así como a la convicción de ser verdaderamente un Nuevo Mundo. Se trata de un argumento acorde con el vitalismo tan del gusto de Aguilera Cerni por influencia de Ortega y Gasset. Este ímpetu hace posible la admirada capacidad de los artistas americanos para liberarse de los academicismos y del gravoso peso de las tradiciones artísticas normativas, cuestión que se vería especialmente encarnada, sobre todo tras su trágica muerte, en la figura de Jackson Pollock (1912-1956), arquetipo del mito americano. Así, podemos leer el arranque de la crónica exultante de un corresponsal de la revista madrileña Goya:

Debo destacar que incluso en una ciudad tan preparada para el arte moderno como es Basilea la exposición [de Pollock] trajo una sensación de novedad, de alegría, de frenesí y de libertad exasperada ${ }^{33}$.

Antes de la aparición, en 1955, de la Introducción a la pintura norteamericana sólo en algunas ocasiones se había visto en España el arte producido en los Estados Unidos. En 1953, en la Exposición Internacional de Arte Abstracto celebrada en Santander, se colgaron obras de Ellsworth Kelly junto a otras de los informalistas españoles Millares y Saura ${ }^{34}$. En 1954, en el barcelonés Palacio de La Virreina, se celebró una muestra de grabado norteamericano, y en otoño de 1955, con motivo de la Tercera Bienal Hispanoamericana de Arte, se exhibió en Barcelona y en Madrid una selección de la colección del Museo de Arte Moderno de Nueva York bajo el título El arte moderno en los Estados Unidos, una exposición que Aguilera calificaría de "histórica" 35 . En la primavera de ese mismo año 1955 se expuso en Madrid una selección de los fondos de pintura americana de la Academia de Bellas Artes de Pensilvania. En el artículo que publicó comentando esta exposición itinerante por Europa, Joseph T. Fraser, a la sazón director de la Academia, agradeció públicamente a la USIA $^{36}$ el haberla organizado:

Esto ha sido posible gracias al interés y a la colaboración de la U.S. Information Agency de Washington, la cual, al enterarse de que la Academia celebra su CL aniversario consideró esta exposición como ideal para realizar una tournée por el extranjero ${ }^{37}$.

33 PINTÓ, 1958, pp. 59-60.

34 Exposición Internacional de Arte Abstracto, celebrada en Santander con motivo del Primer Congreso de Arte Abstracto. Ver Tusell, 2003, pp. 223-232.

35 Exposición "El arte moderno en los Estados Unidos", organizada por el Instituto de Cultura Hispánica en el Palau de La Virreina de Barcelona y el Museo de Arte Moderno de Madrid. ANÓNIMO, 1955a, pp. 58-60; GÁllego, 1955, pp. 42-44; McANDrew, 1955, pp. 104-109; CaBañas Bravo, 1996.

36 United States Information Agency, creada por Eisenhower en agosto de 1953 y disuelta en octubre de 1999, agencia dedicada a la "diplomacia pública". Entre sus cometidos estaban la emisora Voice of America y la dotación del Fulbright Scholarship Program.

${ }^{37}$ La exposición se celebró en la sala de exposiciones de la Dirección General de Bellas Artes del 23 de abril al 6 de mayo. FraSER, 1955, pp. 379-382; ANÓNIMO, 1955b, pp. 58-60. 
La USIA promovía este tipo de iniciativas como parte de la campaña propagandística implementada por los Estados Unidos de cara al exterior en el marco de la Guerra Fría. El arte resultó ser una baza importante, tanto el de los siglos pasados, como sobre todo el contemporáneo, representado por el llamado Abstract Exressionism, pues permitía mostrar al mundo cómo en Estados Unidos se podía crear en total libertad frente a las restricciones que imponía a sus artistas el bloque soviético.

Sin embargo, resulta sorprendente el que los expresionistas abstractos y la vanguardia en general fueran considerados filocomunistas y subversivos en el interior de los Estados Unidos por los mismos años en los que estaban siendo utilizados como propaganda en la política exterior. Un político muy activo en la descalificación del arte moderno durante los años cincuenta, el senador por Missouri George Dondero, declaraba que las pinturas abstractas eran mapas secretos y los artistas espías; que el arte abstracto pretendía destruir América "mediante la confusión de la mente" y otras ideas similares que fueron recibidas positivamente por algunos sectores de la sociedad estadounidense ${ }^{38}$. Entre 1976 y 1977 la promoción oficial del arte estadounidense en el mundo generó varias grandes exposiciones en conmemoración del Bicentenario de su independencia, que recorrieron varias ciudades europeas sin pasar por ninguna española, lo cual provocó la protesta de Julián Gállego, entonces corresponsal en París:

Es de lamentar que, ya que estamos a las crudas, no estemos a las maduras, y que esta exposición no pase por Madrid para ofrecer a nuestros compatriotas una información cultural por encima de toda política ${ }^{39}$.

\section{RECORRIDOS VISUALES Y ESTÉTICOS}

Aguilera ilustró profusamente sus dos libros. En el primero incorporó cuarenta y dos ilustraciones y en el segundo fueron ciento diez, siempre en blanco y negro. La selección de obras cumple el objetivo propuesto, porque ofrece un amplio panorama del arte estadounidense. El autor dio a cada uno de estos escritos una estructura particular. La Introducción a la pintura norteamericana es un recorrido cronológico. En el otro libro, Arte norteamericano contemporáneo, el texto se divide en seis apartados de carácter temático: 1: Contorno, expresión, voluntad; 2: Construcciones para el hombre; 3: El arte en lo útil; 4: Volumen, forma, espacio; 5: La pintura y los pintores; 6: Epílogo. Cada uno de estos capítulos se subdivide a su vez en epígrafes, en los que se combinan cuestiones sociales, estéticas, históricas, comentarios concretos de artistas y de movimientos.

Arte Norteamericano del siglo $X X$ fue publicado por la misma editorial valenciana -Fomento de Cultura Ediciones- en 1957, con un diseño más cuidado y portada realizada por el pintor del grupo El Paso, Manolo Millares. El libro amplía su contenido con la arquitectura y las artes industriales, además de la escultura y la pintura,

38 STONOR SAUNDERS, 2001, p. 352.

39 GÁllego, 1977, pp. 316-318. 
siendo ésta siempre el eje principal del texto y las ilustraciones. Aguilera recuerda la "lucha sorda entre lo nativo y lo importado" 40 , que finalmente se resuelve en un arte maduro en el cual las corrientes internacionales pueden ser transformadas gracias a un substrato activo que las traduce a sus propios términos. En este proceso el crítico valenciano menciona, de nuevo, la magnificencia de la naturaleza de los territorios estadounidenses, haciendo gala de un determinismo geográfico que pudo tomar directamente del libro de John Walker:

Se ha procurado presentar un breve panorama histórico y poner de relieve la relación de los artistas americanos con su medio ambiente y los problemas con que se enfrentaron en una sociedad colonial y provincial, ya que la creación de un estilo pictórico americano va unida a la aparición gradual de una nueva cultura en un mundo nuevo también ${ }^{41}$.

El discurso de Aguilera, sobre todo en el libro de 1957, se detiene a menudo en mostrar los contextos de los que surgen las propuestas artísticas, estableciendo siempre relaciones entre el arte y la sociedad. Este aspecto los sitúa en el entorno de una metodología historiográfica próxima a la historia social del Arte. Es perceptible también el marco culturalista y humanista que Aguilera Cerni recibe de Ortega y Gasset, como también la orientación ideológica, compartida con el historiador del arte italiano Giulio Carlo Argan, que mostrará de forma más abierta en sus escritos de los años sesenta y setenta. El arte es expresión y comunicación, creación inmersa en un sistema de relaciones sociales y económicas en el que manifiesta la tensión entre su origen artesanal y su inmersión en lo industrial y técnico moderno. Lejos de ser puro ejercicio formal y autónomo - tal como lo defiende la crítica formalista y la tendencia conocida como "arte por el arte"-, es ideología y refleja el espíritu de la época con toda su variada vitalidad y complejidad:

Estamos en una civilización donde hay poderosas fuerzas que pretenden el predominio de lo "artístico" - manualidad técnica sin ideología, huérfana de incidencia sobre la configuración del futuro a través de la transformación del presente- sobre lo "estético"42.

El mundo moderno incide en la obra de arte de manera necesaria, como incide también la subjetividad del propio artista, y juntos propician la existencia del estilo, más importante que cualquier noción de belleza:

¿Existe lo bello? ¿Es la belleza lo que ha buscado el creador, históricamente hablando? Las preguntas no son nuevas, pero sí actuales. Lo que se busca es la expresión de un mundo, el mundo del artista, procurando la máxima identificación con el contorno y con las exigencias insoslayables del material empleado. Lo bello no es sino un pozo sin fondo, donde se amontonan las confusiones; un callejón sin salida. Cuando

\footnotetext{
40 Aguilera Cerni, 1957, p. 12.

41 WaLKer, 1954, p. 5.

42 Aguilera CERNI, 1975, p. XIX.
} 
el artista pare una obra intenta comunicarse, expresarse, revelar el contenido y la aspiración de la cultura, el ambiente, la sociedad donde ha sido producido él mismo. No busca la belleza, sino el estilo, la máxima perfección y pureza del milagro estilístico ${ }^{43}$.

En sus libros de los años cincuenta, Aguilera defiende al arte norteamericano por su extraordinaria capacidad para reflejar la época moderna como una "cultura-crisol"44 que da testimonio no solo de lo que sucede en su propio territorio, sino del "paisaje artístico occidental" 45 . Acepta así la posición de liderazgo de los Estados Unidos en el concierto internacional. Más aun, identifica a la nación americana con el concepto de "reserva espiritual de Occidente", hasta entonces privativo de España según la ampulosa retórica franquista:

Mejor o peor, allí se está creando un hombre nuevo. Para bien o para mal, ocupa un puesto rector en el ámbito occidental. No pretendemos convertir las relaciones de tamaño en relaciones de valor, pero sí mantendremos que las reservas espirituales del Occidente son, en gran parte, las que los Estados Unidos han elaborado a lo largo de su avatar histórico ${ }^{46}$.

En el primero de sus libros el recorrido abarca desde Jacques Lemoyne y John White ${ }^{47}$, con sus primeras imágenes de paisajes y nativos de Florida y Carolina del Norte, hasta la abstracción de Arthur Dove (1880-1946) y Willem De Kooning (1904-1997), y el surrealismo social de Walter Quirt (1902-1968), ya en los años cuarenta del siglo XX. En las imágenes dibujadas por Jacques Lemoyne, Aguilera advierte la incapacidad de estos ilustradores europeos para captar la verdadera apariencia de los nativos, razón por la cual interpretaron la anatomía de éstos a través de los ojos del Renacimiento:

Sólo supieron interpretarlas con los medios expresivos en ellos habituales. No pudieron intentar la peligrosa aventura de narrar un mundo virginal sin aferrarse a sus viejos prejuicios [atribuyeron] a los indios anatomías propias de la escultura renacentista y perfiles griegos en los que Leonardo sólo hubiera rechazado la tosca ejecución ${ }^{48}$.

Son pocas las alusiones que hace el autor al substrato nativo de Norteamérica, aunque lo menciona como una de las bases que alientan la producción artística del país. Encontramos sólo una cierta atención, en el segundo de sus libros, a la "dirección indígena", comentando brevemente las creaciones de un tallista de tótems de

43 Aguilera Cerni, 1957, p. 10.

44 Ibidem, p. 60.

45 Aguilera Cerni, 1955, p. 82.

46 Aguilera Cerni, 1957, pp. 21-22.

47 Jacques le Moyne de Morgues (c. 1533-1588) Artista francés que viajó a Florida en 1564 con los exploradores franceses Jean Ribault y Rene de Laudonnière. John White (c. 1549-1593) era un artista inglés que viajó con Richard Grenville en 1585 a Carolina del Norte. Realizó mapas y dibujos de paisajes y pueblos nativos que fueron llevados a grabado más tarde por Theodore de Bry. Ver TuCKER, 2008.

48 Aguilera Cerni, 1955, p. 11. 
Alaska muy reconocido a finales de los años cuarenta: John Wallace ${ }^{49}$. Este artista es mencionado junto a los también escultores Patrocinio Barela y José Dolores López, ambos de Nuevo México ${ }^{50}$, en referencia a un arte indígena escasamente citado por otras fuentes. Este sustrato cultural, activo: "no quiere decir tipismo, ni folklorismo" 51 . Esta atención a la creación de los native americans queda, sin embargo, desdibujada ante la preferencia innegable que concede a los desarrollos creativos más vinculados a la historia del arte occidental canónica. Sin embargo, denota una legítima, aunque tímida, intención de conocer aquellas manifestaciones que se han visto relegadas a los márgenes. Lo vemos en su mención del artista afroamericano Horace Pippin (1888-1946) y en la inclusión de mujeres artistas como, además de la ya citada Mary Cassatt, Georgia O'Keeffe (1887-1986), Irene Rice Pereyra (1902-1971), Loren McIver (1909-1998) y Grace Hartigan (1922-2008). También en la nómina de pintores y escultores casi desconocidos, pero que le sirven para establecer un tejido general de creadores.

\section{EL ARTE DE ESTADOS UNIDOS, ENTRE EL REALISMO Y LA ABSTRACCIÓN}

Aguilera consideraba el "sello distintivo" de la americanidad del arte americano su tendencia al realismo, aderezada con "cierta nota emocional de sonido eminentemente nativo ${ }^{52}$, y con la "entrega a la causa del hombre, nervio vital de todo el arte norteamericano" 53 . Las imágenes del primero de los libros muestran una cantidad mucho mayor de referencias e ilustraciones de pintura figurativa que abstracta, en clara apuesta por la interpretación humanizadora y por el mantenimiento de los códigos de legibilidad de la pintura. Haciendo un breve recuento de las ilustraciones del segundo libro, esta tendencia se mantiene. Las 24 primeras ilustraciones corresponden a arquitectura y diseño, y de las restantes 86, 26 reproducen obras abstractas de escultura y pintura y 60 creaciones figurativas, también entre pinturas y esculturas.

Aguilera Cerni presenta a los grandes "clásicos" de la pintura norteamericana como los grandes puntales sobre los que se ha construido la creación artística posterior. La tendencia al realismo proporcionó episodios de gran calidad, ya en el siglo XIX, con Thomas Eakins (1844-1916), Winslow Homer (1836-1910) y los artistas de la llamada Ash Can School, capitaneados por Robert Henri (1865-1929). Sería este conjunto de realistas del último tercio del XIX y principios del XX el que alimentaría una clara opción por el retrato de la vida, la ciudad, los personajes que en ella habitan y los paisajes humanizados y cargados de una singular épica del trabajo. Esa mirada a la realidad encontraría en la llamada American Scene Painting de los años treinta el paso a una concepción nacionalista y regionalista americana, cuyos representantes más destacados son Thomas Hart Benton (1889-1975) y Grant Wood

\footnotetext{
49 JonAitis, 1989, pp. 237-252.

50 Aguilera Cerni, 1957, p. 79-80.

51 Ibidem, p. 13.

52 Aguilera Cerni, 1955, p. 52.

53 Aguilera Cerni, 1957, p. 35.
} 
(1891-1942) autor, este último, de uno de los iconos estadounidenses por antonomasia: American Gothic, cuadro de 1930. Estos artistas aparecen citados en el contexto del aislacionismo americano más conservador que no solo caracterizó al arte, sino también a la política de un país que quería salir de la Gran Depresión económica.

Fuera del regionalismo, pero todavía dentro del realismo, hallamos en esos años de entreguerras el desarrollo del Realismo Social que para Aguilera Cerni es objeto del mayor interés. Cita brevemente a Edward Hopper (1882-1967), cuya carga emocional no parece interesarle demasiado, rasgo que también subyace en la pintura de Andrew Wyeth (1917-2009), específicamente su famoso cuadro Christina's World de 1948, que califica de "sentimentalismo difícilmente aceptable" 54 . Aguilera se detiene a considerar a otros pintores cuyo lenguaje, realista aunque con influencias a veces expresionistas, a veces surrealistas, logra expresar la angustia de la época y manifiesta una actitud crítica y comprometida hacia todo aquello que les rodea. Valora especialmente la pintura marcada por un fuerte compromiso social de George Bellows (1882-1925), Ben Shahn (1898-1969) y algunos otros como Jack Levine (1915), William Gropper (1897-1977) y Philip Evergood (1901-1973). Estos pintores estaban dispuestos a "combatir con sus armas culturales [...] se trataba de permanecer en la brecha o abandonar el campo al enemigo"55. De todos ellos es Ben Shahn el que personifica al artista social que propugna Aguilera Cerni:

[...] puede afirmarse que es un artista extraordinario. Espíritu airado y sensible, no se resigna al silencio cuando cree contemplar una injusticia ${ }^{56}$.

Aunque el realismo fue aplaudido y gozó de buena consideración entre la crítica y el público americanos, el movimiento artístico que más rentabilidad política produjo internacionalmente fue el Expresionismo Abstracto. Sin duda se trataba de un conjunto excepcional de pintores que lograron mostrar al mundo una forma nueva de abordar la pintura, con formatos, técnicas y conceptos plásticos que renovaron la abstracción. Fue el "triunfo de la pintura americana" 57 , y su éxito totalmente justificado. Aguilera Cerni, más cauto en el primero de sus libros, en su segunda obra dedica más atención a la abstracción norteamericana, que ya ha tenido oportunidad de conocer de primera mano a través de exposiciones en Europa, ya que todavía no había viajado a los Estados Unidos ${ }^{58}$. Al afirmar que "no hace falta ninguna clase de realismo para transcribir plásticamente la vibración contemporánea", admite la capacidad de la abstracción para comunicar y transmitir las pulsaciones de la vida actual, marcada por una vivencia trágica, una "angustiosa niebla contemporánea" 59 . La abstracción es una forma de expresión que responde a la época y, además de las razones

\footnotetext{
54 Ibidem, 1957, p. 109.

55 Aguilera Cerni, 1955, p. 66.

56 Ibidem.

57 Tomo prestado el título del libro de SANDLER, 1996.

58 Según conversación mantenida por la autora de este artículo en París el día 25 de mayo de 2009 con José Garnería, amigo personal de Aguilera y director del Museo de Arte Contemporáneo Vicente Aguilera Cerni de Vilafamés.

59 Aguilera Cerni, 1957, pp. 12, 20.
} 
formales y experimentales propias del medio, sus técnicas y tradiciones propias, posee un aliento fuertemente anclado en la "angustia existencial" que Aguilera menciona aludiendo a Sartre y Unamuno:

Esa terrible angustia existencial de estar colocados entre el ser y la nada no es hoy una mera postura intelectual para decadentes. Es algo que corre mezclado con nuestra sangre y tiñe con una dolorosa y unamunesca tinta de tragedia las vidas de los hombres de este tiempo. Por eso se huye de lo real. Por eso estamos viviendo en plena rebelión de irrealidad contra las realidades del mundo actual ${ }^{60}$.

La abstracción implica un alto grado de experimentalismo, pero también puede ser testimonio vivo de su época por cuanto "es en gran medida una protesta contra la realidad"61. La abstracción americana aparece en los dos libros como una suma de iniciativas individuales de los artistas desde principios de siglo, desde la pintura pionera de Arthur Dove (1880-1946). No menciona específicamente el expresionismo abstracto como tal categoría, ni la escuela de Nueva York, aunque sí la escuela del Pacífico encabezada por Mark Tobey (1890-1976) ${ }^{62}$. Más que hablar de escuelas o grupos, le interesa definir las diversas modalidades de la abstracción, como son

[...] la geometría pura, la geometría de las formas mecánicas y arquitectónicas, la interpretación geométrica de la naturaleza, el expresionismo introspectivo, y la interpretación de las formas naturales ${ }^{63}$.

Es el resultado de un proceso evolutivo propio de los tiempos en el que se conjugan la angustia del individuo moderno con la ciencia y la técnica. También lo es del rechazo a las convenciones de la Academia y de la tradición más inmovilista. Para Aguilera, este mapa de la abstracción no traza fronteras cerradas entre modalidades, dando cabida a posiciones eclécticas. Este componente trágico, de comunicación interpersonal de una angustia existencial, considerada como producto de la época y compartida por muchos seres humanos, es precisamente lo que Aguilera Cerni más valora del expresionismo abstracto americano. Rechaza abiertamente considerarlo como un ejercicio puramente formal, y en este sentido hay que recordar que una parte importante de la crítica, e incluso de los artistas incluidos más o menos laxamente en esta etiqueta, participaban de esta concepción. Por ello, Aguilera dejaría claro qué actitud valoraba y cual no. En su artículo "El arte, además" de 1959, contrapone la actitud comprometida de Robert Motherwell (1915-1991) y Theodoros Stamos (1922-1997) a la postura arte-por-el-arte que considera superficial de Sam Francis (1923-1994), Arshile Gorky (1904-1948) y Clyfford Still (1904-1980):

Lo raro, lo excepcional, lo que se sale de esas vaguedades más o menos presuntuosas, es oír a Motherwell afirmar: "sin conciencia ética un pintor es sólo un decorador [...] Sin la conciencia ética, el auditorio es sólo sensual, únicamente de estetas". O

60 Aguilera Cerni, 1955, pp. 74-75.

61 Ibidem, p. 73.

62 Aguilera Cerni, 1957, p. 116.

63 Aguilera Cerni, 1955, p. 76. 
escuchar a Stamos algo sencillo y humilde: "pintar, en su expresión más alta, consiste en ser honrado con lo que uno pinta, con uno mismo, con su propia época y -sobre todo- con su Dios y con sus sueños" ${ }^{2}$.

En un artículo dedicado a Willem de Kooning (1904-1997) Aguilera manifestaría una vez más su visión: la pintura de este artista, en su forma externa puede producir rechazo y desagrado - ¿entendemos que también a él?-, pero transmite plenamente la angustia y el conflicto interno del ser humano y la época:

[...] lo que nos puede desagradar de la pintura de Willem de Kooning es exactamente lo que nos transcribe -con evidente crudeza- del vacío, la distorsión y la angustia afectivamente existentes 65 .

En su rechazo de la estética formalista, Aguilera hubiera podido suscribir las palabras de Mark Rothko (1903-1970): "Preferiría dotar de atributos antropomórficos a una piedra antes de privar de humanidad a la más ligera posibilidad de conciencia"66.

La posición teórica de Aguilera en el contexto español de los años cincuenta y sesenta se hizo fuerte en esta consideración de la obra de arte como comunicación humana cargada de sentido ético y de ideología. Su criterio estaba abierto a aceptar posiciones que podían parecer contrapuestas, como la figuración y la abstracción. Claro que en la España de la época, el eclecticismo y la diversidad de tendencias estaba siendo una opción válida. Se podía apostar por un arte nuevo, vivo y actual desde ambos lenguajes, siempre que hubiera en las obras un contenido y un compromiso. Esta actitud de Aguilera cobra todo su sentido en los años de la fundación del valenciano Grupo Parpalló en 1956, pues había que legitimar posiciones variadas en lo formal, tanto abstractas como figurativas, pero unidas por un mismo deseo de rechazo de lo académico y apuesta por la modernización y el compromiso del arte realizado en España, con el contexto general de una resistencia cultural antifranquista. Aguilera, como fundador de Parpalló, se planteaba despertar la vida artística de Valencia, y la primera fase del grupo aglutinó a artistas de muy diferentes tendencias. Sabía que el debate sobre el arte abstracto ya contaba en España con un importante recorrido desde finales los años cuarenta. La "Escuela de Altamira", el "Grupo Pórtico", la exposición de arte abstracto de 1953, y los congresos, debates y publicaciones sobre ello, además de los escritos de Ángel Ferrant ${ }^{67}$, Ricardo Gullón 68 o Juan Eduardo Cirlot $^{69}$ entre otros, habían dado presencia a la abstracción y se reflexionaba sobre ella. En la ultraconservadora iglesia católica española de los años cincuenta se admitía incluso, de la mano del Padre Alfonso Roig, la posibilidad de incorporar obras abstractas en las iglesias, valorándolas como portadoras de espiritualidad ${ }^{70}$.

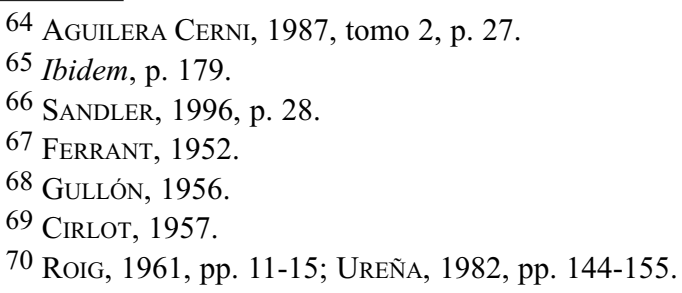


Era un momento histórico de ruptura progresiva del aislamiento político del régimen que desembocaría, en 1957, en una modernización materializada en la potente generación abstracta de los grupos recién formados: "El Paso" y "Equipo 57".

En 1958 el Expresionismo Abstracto americano gozaba ya de un gran reconocimiento. En el verano, en el Museo de Arte Contemporáneo de Madrid se celebró una magna exposición, La Nueva Pintura Americana, que consagraría definitivamente la relevancia artística y la madurez del arte de Estados Unidos. En el texto del catálogo, escrito por el director del MoMA de Nueva York, el acento se ponía en la libertad creativa, el compromiso y la actitud existencial de los pintores americanos, algo que alentaba también los escritos de Aguilera y el sentir de muchos artistas españoles de la vanguardia:

Con una actitud desafiante rehúsan el aceptar los valores convencionales de la sociedad que los rodea, pero no están comprometidos políticamente, aunque sus obras sean elogiadas y condenadas como demostraciones simbólicas de la libertad en un mundo en el que la libertad implica una actitud política ${ }^{71}$.

En estos dos libros sobre arte norteamericano, el crítico valenciano nunca trató de establecer una conexión de causa-efecto entre el arte de Estados Unidos y el arte español. Los artistas españoles del entorno informalista conocían lo que se hacía en Estados Unidos, aunque conocían mejor lo que se estaba haciendo en Francia y otros países europeos. En 1958, dos años después de la muerte de Jackson Pollock, Antonio Saura (1930-1998) escribía unas notas en las que le reconocía la condición de "maestro"72. Manolo Millares (1926-1972), por su parte, escribiría en 1959 sobre Franz Kline resumiendo un sentimiento que Vicente Aguilera Cerni y otros muchos habían expresado en esos convulsos tiempos:

¿De dónde el orden y la armonía cuando la destrucción y la angustia nos poseen casi totalmente? No existe más solución en el arte que la aventura total, su riesgo, y las posibilidades que la comportan. Franz Kline es un hombre que llega al límite, pero no se detiene allí en miramientos; se mete en la mar tenida por tenebrosa y arranca nuevas parcelas a mundos nuevos, desconocidos hasta entonces ${ }^{73}$.

\section{CONCLUSIONES}

La redacción de estos dos libros sobre arte de los Estados Unidos se produjo en un contexto en que, a pesar de las restricciones, el país quería mostrar una cierta voluntad de modernización. En la década de los cincuenta la actividad artística se desarrollaba con fuerza a pesar de las tendencias ultraconservadoras imperantes. Importantes grupos artísticos, debates y publicaciones eran el síntoma de un claro deseo de renovación. Los escritos de Aguilera Cerni se propusieron dar a conocer los principales hallazgos del arte en Estados Unidos para paliar la escasa información

71 BARR, 1958, p. 4.

72 Toussaint, 1983, p. 217.

73 Calvo Serraller, 1985, vol. I, p. 451. 
existente sobre una nación de creciente influencia internacional, a la que el régimen se quería aproximar. No hay que entenderlos como una investigación teórica ni crítica. Sí son oportunos al dar a conocer a Estados Unidos como una potencia también en lo cultural, con un arte en plena madurez. Aguilera Cerni no se pronuncia ni emite una opinión sobre la política cultural norteamericana. Su posición es la del que asume la tarea necesaria de mostrar creaciones artísticas casi desconocidas para el público y muchos de los artistas en la España de entonces. El suyo es un recorrido panorámico que quiere incluir un gran número de exponentes del arte y la arquitectura, y lo hace siguiendo un orden cronológico y estilístico. No pretende arrojar conclusiones sobre las concomitancias entre el arte estadounidense y el que se hacía entonces en España. La suya es, por así decir, la actitud de un narrador atento que busca cierta objetividad. Es sensible a la multiplicidad de opciones estéticas, defendiendo especialmente a algunos movimientos comprometidos ideológicamente (el realismo social) frente a otros más formalistas, lo que da cumplida cuenta de sus propios posicionamientos en aquellos años. Apoyándose en una bibliografía históricoartística apenas conocida en nuestro país, su mirada sobre el arte norteamericano quiere ser abierta y está muy marcada por su propia concepción filosófica del arte, de inspiración orteguiana. El arte de Estados Unidos es para Aguilera un crisol de tendencias y aspiraciones, deseos y contradicciones no sólo estéticos, sino propios de la época en general. Esta dimensión metafórica de la creación artística, sobre todo en algunos pasajes donde relaciona la pintura abstracta con la angustia del hombre moderno, es signo claro de su percepción de una humanidad fragmentada contemplada con pesimismo pero, al mismo tiempo, aliviada por la confianza en una cierta capacidad terapéutica del arte.

\section{REFERENCIAS BIBLIOGRÁFICAS}

AA.VV.

1961 La pintura informalista a través de los críticos. Madrid. Dirección General de Relaciones Culturales.

1990 Relaciones artísticas entre España y América. Madrid. CSIC.

A. F.

1954 "Reseña de CARTIER, Raymond. Las 48 Américas". Nuestro Tiempo. Pamplona. $n^{\circ} 1$, pp. 125-126.

Aguilera Cerni, Vicente

1955 Introducción a la pintura norteamericana. Valencia. Fomento de Cultura Ediciones.

1957 Arte norteamericano del siglo XX. Valencia. Fomento de Cultura Ediciones.

1975 "Prólogo". En ARgan, Giulio Carlo. El arte moderno 1770-1970. Valencia. Fernando Torres Editor, pp. XV-XXI.

1976 Arte y compromiso histórico (Sobre el caso español). Valencia. Fernando Torres

1987 Textos, pretextos y notas. Escritos escogidos, 1953-1987. Valencia. Ayuntamiento. 
ANÓNIMO

1955a "Notas de Nuestro Tiempo. América en la Bienal”. Nuestro Tiempo. Pamplona. $\mathrm{n}^{\mathrm{o}} 16$, pp. 58-60.

$1955 b$ "Notas de nuestro tiempo. Pintores de Estados Unidos". Nuestro Tiempo. Pamplona. $\mathrm{n}^{\mathrm{o}}$ 10, pp. 58-60.

Ashton, Dore

1988 La Escuela de Nueva York. Madrid. Cuadernos Arte Cátedra.

BARKER, Virgil

1950 American Painting: History and Interpretation. New York. The Macmillan Company.

BARR, Alfred H.

1958 The New American Painting. La Nueva Pintura Americana. Madrid. Museo Nacional de Arte Contemporáneo.

1989 La definición del arte moderno. Madrid. Alianza Forma.

Cabañas Bravo, Miguel

1996 La política artística del franquismo: el hito de la Bienal Hispanoamericana. Madrid. CSIC.

Calvo Serraller, Francisco

1985 España. Medio siglo de arte de vanguardia. 1939-1985. Madrid. Fundación Santillana y Ministerio de Cultura.

CARNDUfF Ritchie, Andrew

1951 Abstract Painting and Sculpture in America. New York, Museum of Modern Art.

Cirlot, Juan Eduardo

1957 El Arte Otro. Informalismo en la escultura y pintura más recientes. Barcelona. Seix Barral.

Collar, Jorge

1955 "Walt Disney, técnica y fantasía". Nuestro Tiempo. Pamplona. n 14, pp. 100-113.

1957 “Más dibujos de Walt Disney”. Nuestro Tiempo. Pamplona. n 34, pp. 453-454.

Correyero Ruiz, Beatriz

2003 "La propaganda turística española en los años del aislamiento internacional”. Historia y Comunicación Social. Madrid. nº 8, pp. 47-61.

E. R.

1961 “Reseñas. Cine. Walt Disney”. Nuestro Tiempo. Pamplona. nº 82, p. 523.

DíAz SÁnChEZ, Julián - Llorente HernándeZ, Ángel

2004 La crítica de arte en España (1939-1976). Madrid. Istmo.

FARRÉ GUAL, Esteban

1955 "Las películas del oeste”. Nuestro Tiempo. Pamplona. n 9, pp. 41-49.

1959 “Crónicas. Los films del Oeste. Duelo de titanes”. Nuestro Tiempo. Pamplona. no 61, pp. 98-104. 
FERRANT, Ángel

1952 La esencia humana de las formas. Madrid. Publicaciones de la Escuela de Altamira.

FLEXNER, James Thomas

1947 American Painting. First Flowers of Our Wilderness. Boston. Houghton Mifflin - Riverside Press.

FRASER, Joseph T.

1955 "CL aniversario de la Academia de Pensilvania". Goya. Madrid. n 6, pp. $379-382$.

GÁLLEGO, Julián

1955 "Crónica de París. Franceses en América y americanos en París". Goya. Madrid. $\mathrm{n}^{\mathrm{0}}$ 7, pp. 42-44.

1977 "Carta de Roma. 200 años de pintura americana". Goya. Madrid. nº 37, pp. 316-318.

García Felguera, $\mathrm{M}^{\mathrm{a}}$ de los Santos

2001 "Americanos en Europa: la recepción de los paisajistas del siglo XIX". En AA.VV. Explorar el Edén. Paisaje americano del siglo XIX. Madrid. Museo Thyssen-Bornemisza, pp. 47-61.

GROSECLOSE, Barbara

2000 Nineteenth-Century American Art. Oxford-New York. Oxford University Press.

Guilbaut, Serge

2007 De cómo Nueva York robó la idea de arte moderno. Valencia. Tirant lo Blanc.

Gullón, Ricardo

1956 El arte abstracto y sus problemas. Madrid. Publicaciones de Cultura Hispánica.

Hess, Thomas B.

1951 Abstract Painting: Background and American Phase. New York. Viking Press.

JARQUE ÍÑIGUEZ, Arturo

1998 Queremos esas bases. El acercamiento de Estados Unidos a la España de Franco. Alcalá de Henares. Universidad de Alcalá.

JIMÉNEZ-BLANCO CARRILLO DE ALBORNOZ, $\mathrm{M}^{\mathrm{a}}$ Dolores

1998 Arte y Estado en la España del siglo XX. Madrid. Alianza Editorial.

JONAITIS, Aldona

1989 "Totem Poles and the Indian New Deal". The Canadian Journal of Native Studies. Manitoba (Canadá). vol. IX. nº 2, pp. 237-252.

LARKIN, Oliver W.

1949 Art and Life in America. New York. Rine, Hart and Company.

LLEONART ANSÉLEM, Alberto

1995 "El ingreso de España en la ONU: obstáculos e impulsos". Cuadernos de Historia Contemporánea. Madrid. n 17, pp. 101-119. 
LLORENTE HERNÁNDEZ, Ángel

1995 Arte e ideología del franquismo (1936-1951). Madrid. Visor.

MCANDREW, John

1955 "Artistas norteamericanos en la Bienal de Barcelona". Goya. Madrid. n

NiÑO, Antonio

8, pp. 104-109.

2003 "50 años de relaciones entre España y Estados Unidos". Cuadernos de

PACK, Sasha D Historia Contemporánea. Madrid. $\mathrm{n}^{\circ}$ 25, pp. 9-33.

2009 La invasión pacífica. Los turistas y la España de Franco. Madrid. Turner.

PAYRó, Julio E.

1946 Arte y artistas de Europa y América. Ayer y Hoy en Francia, Bélgica, Holanda, Gran Bretaña, España, Argentina, Chile, Uruguay y Estados Unidos. Buenos Aires. Editorial Futuro.

Payne, Stanley G.

2003 "Los Estados Unidos y España: Percepciones, imágenes e intereses". Cuadernos de Historia Contemporánea. Madrid. no 25, pp. 155-167.

PinTó, Alfonso

1958 “Crónica de Suiza. Jackson Pollock". Goya. Madrid. nº 25, pp. 59-60.

Rose, Barbara

1967 American Art since 1900. A Critical History. New York. Praeger.

SANDLER, Irving

1996 El triunfo de la pintura norteamericana. Historia del expresionismo abstracto. Madrid. Alianza Editorial.

SueIRo, Susana

2008 Posguerra. Publicidad y Propaganda (1939-1959). Madrid. Sociedad Estatal de Conmemoraciones Culturales.

RoIG, Alfonso

1961 "La mística en el arte español”. En AA.VV., pp. 11-15.

STONOR SAUNDERS, Frances

2001 La CIA y la Guerra Fría cultural. Madrid. Editorial Debate.

TOUSSAINT, Laurence

1983 "El Paso" y el arte abstracto en España. Madrid, Cátedra.

TUCKER, Abigail

2008 "Sketching the Earliest Views of the New World". Smithsonian Magazine. Washington D.C. December. Versión digital: www.smithsonianmag.com/people-places/Brave-New-World.html

Tusell, Genoveva

2003 "La internacionalización del arte abstracto español: el intercambio de exposiciones con los Estados Unidos (1950-1964)". Espacio, Tiempo y Forma. Madrid. Serie VII. Ha del Arte. $\mathrm{n}^{\mathrm{o}}$ 16, pp. 223-232.

UREÑA, Gabriel

1982 Las vanguardias artísticas en la postguerra española 1940-1959. Madrid. Istmo. 
VIÑAS, Ángel

1981 Los pactos secretos de Franco con los Estados Unidos. Bases, ayuda económica, recortes de soberanía. Barcelona. Grijalbo.

2003a "La negociación y renegociación de los acuerdos hispano-norteamericanos, 1953-1988: una visión estructural". Cuadernos de Historia Contemporánea. Madrid. $\mathrm{n}^{\circ}$ 25, pp. 83-108.

2003b En las garras del águila. Los Pactos con Estados Unidos, de Franco a Felipe González (1945-1995). Barcelona. Crítica.

WALKER, John

1954 La Pintura Norteamericana. Barcelona. Seix Barral.

WigHT, Frederick S.

1949 Milestones of American Painting in Our Century. Nueva York. Chanticleer Press. 